\title{
Evaluation of Bone Regeneration Efficacy in a Rabbit Model of Femoral Condyles Defect by Polyphenols- Containing Bone Filler
}

\author{
Giorgio Iviglia ${ }^{1}$, Clara Cassinelli ${ }^{1}$, José L. Peris-Serra ${ }^{2,3}$, Victor Primo-Capella ${ }^{2,3}$ and Marco Morra ${ }^{1, *}$ \\ ${ }^{1}$ Nobil Bio Ricerche srl, V. Valcastellana 26 - 14037, Portacomaro (AT), Italy \\ ${ }^{2}$ Instituto de Biomecanica de Valencia, Universitat Politecnica de Valencia, Building 9C, Camino de Vera s/n, 46022 Valencia, Spain \\ ${ }^{3}$ Healthcare Technology Group (GTS-IBV), Networking Biomedical Research Centre in Bioengineering, Biomateriales and Nanomedicine (CIBER- \\ $\mathrm{BBN})$, Spain
}

${ }^{\star}$ Corresponding author: Dr. Marco Morra, Nobil Bio Ricerche srl, V. Valcastellana 26 - 14037, Portacomaro (AT), Italy; E-mail: mmorra@nobilbio.it

Received: November 05, 2020; Accepted: November 13, 2020; Published: November 15, 2020

\begin{abstract}
The purpose of this study was to evaluate the local biological effects and bone regeneration efficacy of a polyphenols-enriched ceramic bone filler. To this end, a test article (NBR_Purple) a biphasic phosphate ceramic plus polyphenols from grape pomace and the same material without polypohenols (NBR_White), were implanted in the medial condyle of the femur bone of rabbits for 56 days. A control article of clinical use (Ostim $\left.{ }^{\circledR}\right)$, was implanted as the first control condition. There was a second control by performing the same defect at the same location but without any implanted material (void condition). Histological examination at the end of the test period shows statistically significant improvement of bone regeneration by the polyphenolenriched material over the same material without polyphenols, supporting literature data on the involvement of polyphenol molecules in bone regeneration pathways.
\end{abstract}

Keywords: Bone filler, Polyphenols, In vivo test, Osteointegration, Histology

\section{Introduction}

Replacement of bone loss or reconstruction of bone defect is still a clinical challenge. Different type of bone substitutes are used in clinical practice for treating bone defect caused by trauma, osteoporosis or dental pathology such as periodontitis [1,2]. The mode of action of the biomaterials available on the market mainly relies on mechanical support and is thus limited to providing a functional scaffold for cell adhesion. Synthetic bone fillers, mostly based on calcium phosphate materials, have been widely used due to their good reproducibility, biocompatibility, non-immunogenicity, and also because they offer the opportunity of advanced material engineering [3,4]. Hydroxyapatite (HA) and $\beta$-tricalcium phosphate $(\beta$-TCP) are widely used in bone tissue engineering as bone filler particles $[5,6]$.

Polyphenols are chemical compounds synthetized by plants, widely diffused in the vegetable kingdom. They exert a defense action. Grape is among fruits which contain high quantity of polyphenols, in particular red grape $[7,8]$. The involvement of different classes of polyphenols in molecular pathways that can involve the regeneration of bone tissue is widely studied [9-13]. A role for polyphenols in the local control of inflammatory diseases leading to bone loss, such as periodontitis or osteoporosis, has been discussed in the literature [14-23]. Coupling of polyphenols to ceramic bone fillers could spawn a new generation of materials for bone regeneration, endowed with mechanical support and biological stimulation properties. In this work we describe the in vivo outcomes of a calcium phosphate bone filler containing polyphenols from red grape pomace, implanted for 56 days in the medial condyle of the femur bone of rabbits, showing that the presence of polyphenols enhances bone regeneration properties of the biomaterial.

\section{Materials}

All chemicals were analytical-reagent grade and were purchased from Sigma-Aldrich. Red grape pomace was purchased from a local winery producer (Croatina grape from ALEMAT, Penango, AT, Italy). Ultra-pure (MilliQ) water was used for the preparation of aqueous solutions. Commercially available bone filler Ostim ${ }^{\bullet}$ has been purchased on the market.

\section{NBR_White}

HA was used for enhancing the mechanical strength of scaffold, whereas $\beta$-TCP for its degradability; they were mixed in a percentage of $50 \mathrm{wt} . \%$, respectively, to reach an optimum compromise between the two properties. The ceramic scaffolds were prepared by mixing HA and $\beta$-TCP powders (47 wt.\%) with a binding agent (poly (vinyl alcohol), $3 \mathrm{wt} . \%$ ), and ultrapure water (50 wt.\%) to obtain a ceramic slurry. Dolapix CE 64 was added as a dispersing agent (1 wt.\% of the solid load). The polyurethane (PU) sponge impregnation method was used to obtain a macroporous ceramic scaffold $[24,25]$. A commercial PU sponge slab (45 ppi) of $200 \times 200 \times 10 \mathrm{~mm}^{3}$ was soaked into the 
ceramic slurry for $90 \mathrm{~s}$, followed by compression along the transverse plane $(40 \mathrm{kPa})$ and left at room temperature for $5 \mathrm{~min}$ before repeating the cycle. Impregnation/compression cycles were repeated for 3 times. The ceramic-coated PU sponge was left to dry overnight at $37^{\circ} \mathrm{C}$ and sintered in a furnace at $1100^{\circ} \mathrm{C}$ for $12 \mathrm{~h}$ in air (heating rate $5^{\circ} \mathrm{C} / \mathrm{min}$ ), in order to obtain a porous HA/ $\beta$ TCP slab of $200 \times 200 \times 10 \mathrm{~mm}^{3}$ (a volumetric retention of $24 \%$ was calculated). The obtained porous slab was grinded by a jaw crusher (BB 50, Retsch) and sieved in order to obtain a $300 \mu \mathrm{m}-1000 \mu \mathrm{m}$ porous grained granulate (ceramic granulate, CG). To make the material injectable, the obtained particles were mixed with a $0.5 \% \mathrm{v} / \mathrm{v}$ solution of Collagen from porcine source in a rate of 90:10 granulate:collagen solution.

\section{Preparation of Polyphenols Rich Pomace Extract}

Croatina grape pomace was received in dry form from the producer and stored at $-20^{\circ} \mathrm{C}$ under vacuum until the beginning of the extraction process. In order to make them suitable for the extraction process, grape pomace were first washed with acidified water, dried in a circulating-air oven $\left(37^{\circ} \mathrm{C} \pm 5^{\circ} \mathrm{C}\right)$ and grinded in a bladed mill (GM 200, Retsch). The milled grape pomace ( $300 \mathrm{~g}$ ) were extracted in $2000 \mathrm{~mL}$ of 50:50 acetone:water (v/v) by using an automatic extractor (TIMATIC Micro C). The extraction cycle is fully automatic and alternates a dynamic phase, performed at a programmed pressure, and a static phase in which a forced percolation is generated, which, thanks to the programmable recirculation, ensures a continuous flow of solvent to the interior of the plant matrix thus avoiding oversaturation. Next, the extracted solution was concentrated under reduced pressure in a rotavap and maintained in fridge between $2-4^{\circ} \mathrm{C}$. Full characterization of the polyphenols enriched extracts is provided in reference [26]. As reported in the just quoted paper, main identified components include gallic acid $(9.42 \mu \mathrm{g} / \mathrm{ml})$, caffeic acid $(1.59 \mu \mathrm{g} / \mathrm{ml})$, cumaric acid $(0.21 \mu \mathrm{g} / \mathrm{ml})$, quercetin $(2.06 \mu \mathrm{g} / \mathrm{ml})$, rutin $(0.19 \mu \mathrm{g} / \mathrm{ml})$, malvidin-3-glucoside $(37.2 \mu \mathrm{g} / \mathrm{ml})$. This deeply purplestained croatina grape pomace extract shows a total anthocyanin content of $446.7 \mu \mathrm{g} / \mathrm{ml}$ [26].

\section{NBR_Purple}

NBR_Purple was produced by soaking the ceramic granulate with the Polyphenols rich pomace extract in a percentage of $40 \%$ and $60 \%$ respectively, followed by a $24 \mathrm{~h}$ of evaporation process which allows the ceramic granulate to be enriched with the polyphenol molecules (Pph). Then, the ceramic granulate functionalized with polyphenols were mixed with $0.5 \% \mathrm{v} / \mathrm{v}$ collagen solution from porcine source, in the ratio 90:10, to make the material injectable.

\section{Study Design}

Review and approval by the Ethical Committee of the Universidad Politécnica de Valencia were obtained prior to conduct of the study. For each rabbit, one defect measuring approximately $2 \mathrm{~mm}$ x $5 \mathrm{~mm}$ deep was created in each medial condyle at a distal position of the femur. A second defect measuring approximately $2 \mathrm{~mm} \times 10 \mathrm{~mm}$ deep was created in each medial condyle at a proximal location of the femur (Figure 1). For that reason, each animal had four defect sites, two on each medial condyle. Three different materials and a void were implanted on each animal. The response of NBR_Purple material (test

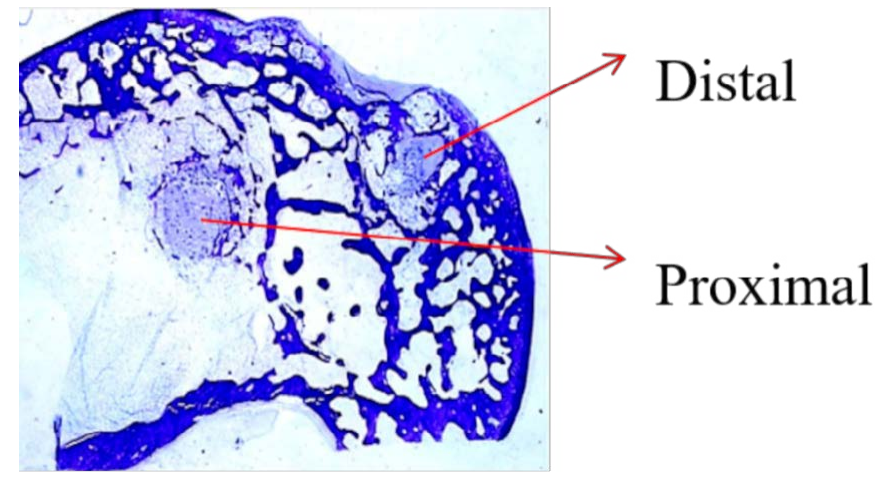

Figure 1: Proximal and distal locations of bone defects at the medial condyle of rabbit femur.

article) was compared to NBR_White (control article), Ostim ${ }^{\bullet}$ and void. Ostim ${ }^{\circledR}$ is a synthetic nanocrystalline HA bone graft, containing about $65 \%$ water and $35 \%$ nanostructured HA particles. Evaluations were conducted at 56 days.

This study had two end-goals:

1) Evaluation of local biological effects after implantation based on the requirements of ISO 10993-6:2007 (Annex E) [27].

2) Performance study by the analysis of \% area occupied by trabecular bone.

Distribution of materials in distal and proximal sites at the right and left femoral condyle are reported in Table 1.

\section{Animal Test System}

Eight New Zealand White rabbit were used for the study. Characteristics Of the animals are reported in Table 2. The rabbit is widely used for evaluation articles intended for clinical implantation.

Table 1: Distribution of materials in distal and proximal sites.

\begin{tabular}{|c|c|c|c|c|c|}
\hline & & \multicolumn{2}{|c|}{ Right condyle } & \multicolumn{2}{c|}{ Left condyle } \\
\hline Animal \# & Cage \# & Distal & Proximal & Distal & Proximal \\
\hline 481 & 2 & NBR_Purple & NBR_White & Ostim & Void \\
\hline 482 & 3 & Void & NBR_Purple & NBR_White & Ostim \\
\hline 483 & 4 & Ostim & Void & NBR_Purple & NBR_White \\
\hline 484 & 5 & NBR_White & Ostim & Void & NBR_Purple \\
\hline 486 & 7 & Void & NBR_Purple & NBR_White & Ostim \\
\hline 487 & 8 & Ostim & Void & NBR_Purple & NBR_White \\
\hline 488 & 9 & NBR_White & Ostim & Void & NBR_Purple \\
\hline 489 & 10 & NBR_Purple & NBR_White & Ostim & Void \\
\hline
\end{tabular}

Table 2: Test system characteristics.

\begin{tabular}{|l|l|}
\hline Species & Rabbit (Oryctolagus cuniculus) \\
\hline Breed & New Zealand White \\
\hline Source & ISOQUIMEN \\
\hline Sex & Female \\
\hline Body Weight Range & $3.6 \mathrm{~kg}$ to $4.0 \mathrm{~kg}$ at implantation \\
\hline Age & Approximately 20 weeks at implantation \\
\hline Other conditions & Nulliparous, skeletally mature \\
\hline Acclimatation period & 2 weeks at IBV animal facilities \\
\hline Number of animals & Eight \\
\hline Identification method & Ear tag and cage card \\
\hline
\end{tabular}


The medial condyle of the femur provides a cancellous bone site, which will mimic the bone sites of clinical use. The rabbit is a small common laboratory species with bones of sufficient size to provide meaningful data and it is accepted by ISO 10993-6:2007 as experimental animal [27]. Any response to the implanted article can be graded and compared to that of a control article.

The rabbits were weighed. Pre-anaesthetic and anaesthetic procedures are described in Table 3. The analgesic protocol is described in Table 4. Each rabbit received an intramuscular injection of the antibiotic enrofloxacin at $10 \mathrm{mg} / \mathrm{kg}$. After the anaesthetic had taken effect, rabbits were clipped free of fur over the lateral and medial aspects of the rear legs from the wing of the illium to the tarsus. The surgical sites were painted with povidone iodine and draped.

\section{Implantation Procedure}

The surgical site was draped, using sterile technique, the medial aspect of the distal epiphysis of the femur over the medial condyle was exposed through a routine surgical approach. Following exposure of the bone, an initial first pilot hole was created, using a drill with an approximate $1 \mathrm{~mm}$ bit, centred between the distal border of the epiphysis and the insertion of the medial head of gastrocnemial muscle. Using a power drill with an approximate $2 \mathrm{~mm}$ drill bit, the hole was enlarged to approximately $2 \mathrm{~mm}$ in diameter. This distal defect had an approximate depth of $5 \mathrm{~mm}$, which it was controlled with a depth gauge placed in the drill. The material was implanted following the distribution shown in Table 1. A second defect (proximal site) was created in a similar way approximately 2-3 mm away from the first implantation site. In this proximal site, the implanted material follows the distribution shown in Table 1. The proximal defect had an approximate depth of $10 \mathrm{~mm}$. The articles were placed in the bone defect to fill the void and remain flush with the cortical surface. The fascia and subcuticular layer were closed with 4-0 absorbable suture and the skin was closed with an intradermal suture technique. The day of implantation was designated as Day 0. A similar procedure was followed to create the other two bone defects on the contralateral medial condyle. The materials were implanted following the distribution shown in Table 1. Two materials on each medial condyle and four materials per animal were implanted.

Each rabbit was moved to a recovery area and was monitored for recovery from anaesthetic. Once sternal recumbency was achieved, each rabbit was returned to its cage. Analgesic protocol is shown in Table 4.
Rabbit were observed daily for general health, especially at the incision site. Body weights were recorded for all animals prior to implantation, and weekly thereafter and prior to termination.

\section{Terminal Procedures}

At 56 days after implantation, the eight rabbits were euthanized. Rabbits were weighed and each rabbit was euthanized with an intravenous injection of sodium pentobarbital-based euthanasia solution. The bone implant sites and adjacent muscle tissue were examined macroscopically and the observations were recorded. Any adverse observations at the implant sites were described. Each femur was dissected free and removed. Femurs were cut as appropriate to allow the fixative (ethanol 70\%) to penetrate the bone tissue for proper fixation.

\section{Histological Procedures}

Histological procedures based on undecalcified bone samples embedded in PMMA to be cut with rotary microtome are published elsewhere [28]. The defect sites with implants in place were removed by making transverse cuts through the bone proximal and distal to each implant site, taking care not to disturb the sites themselves. Each bone section was labelled to indicate its original location. From 4 to 7 slides for each block was prepared as a transverse section of the bone through the diameter of the defect and stained with toluidine blue at $\mathrm{pH}$ 3.5. The identity (animal number, left/right) of each bone section was maintained during processing. Each slide shows a transverse section of the medial condyle with both implantation sites (Figure 1).

The slides related to NBR_Purple and NBR_White were provided to a pathologist for the evaluation of local biological effects after implantation following the criteria described in Annex E of ISO 10993-6:2007 [27]. Six fields (400x magnification) were analysed for each of the slides, totalizing between 24 and 42 fields for the defects analysed of each independent specimen. The histological evaluation was done following standardized procedures of our laboratory. The quantification of the biological effects has been done following the instructions of the ISO 10993-6:2007 standard. In this study 16 different specimens corresponding to an epiphyseal section from both the left and right extremities of rabbit femur have been included. The specimens were toluidine blue-stained.

Table 3: Pre-anaesthetic and anaesthetic procedures.

\begin{tabular}{|l|c|c|c|}
\hline Phase & Product & Via & Concentration $[\mathbf{m g} / \mathbf{m L}]$ \\
\hline Pre-anaesthesia & Xylazine Clorhydrate & IM & 20 \\
\hline Pre-anaesthesia & Ketamine Clorhydrate & IM & 3.12 \\
\hline Anaesthesia-Induction & Propofol & IV & 17.5 \\
\hline Anaesthesia-maintenance & Propofol & IV & 3 \\
\hline
\end{tabular}

Table 4: Analgesic procedure.

\begin{tabular}{|l|c|c|c|c|}
\hline Phase & Product & Via & Dosis $[\mathbf{m g} / \mathbf{k g}]$ & Concentration $[\mathbf{m g} / \mathbf{m L}]$ \\
\hline Pre-surgical & Butorphanol tartrate & IM & 0.4 & 10 \\
\hline Post-surgical immediate & Fluxin meqlumine & SC & 1 & Once \\
\hline Post-surgical immediate & Butorphanol tartrate & IM & 0.4 & Once \\
\hline Post-surgical deferred & Butorphanol tartrate & IM & 0.4 & 10 \\
\hline
\end{tabular}




\section{Evaluation of Local Biological Effects}

Microscopic analysis revealed two areas of interest in each of the specimens included one closer to the medullary canal (proximal region) and the other one localized further from that (distal region). In the bone defects, the testing biomaterials have been implanted. In some cases the defects were left empty to serve as control. The cavities have a spheroid shape and the diameter ranges from 1.10 to 4.28 $\mathrm{mm}$. In the surgical entry, a thickening of fibrotic dense connective tissue could be observed which in some cases presented biomaterial fragments, probably due to the surgical procedure. In these cases connective organized structures associated with these fragments could be observed. This connective tissue is characterized by fibroblasts and macrophages accumulation as well as by an increased vascularization.

\section{NBR_Purple Material}

NBR_Purple material was implanted in 8 specimens, 4 of them corresponding to right and 4 to left condyles. In 4 specimens the implant area is located in the proximal region, while in the other 4 in the distal region. Between 7 and 4 slides of each specimen were included in this study.

\section{NBR_White Material}

This biomaterial was implanted in 8 specimens, 4 corresponding to right and 4 to left condyles. In 4 specimens the biomaterial was implanted in the proximal region and in the other 4 in the distal region. 4-6 slides for each of the specimens were included in this study. Quantitative analysis was performed at $400 \mathrm{x}$ magnification in 6 representative fields of each of the slides included in the study.

\section{Distal}

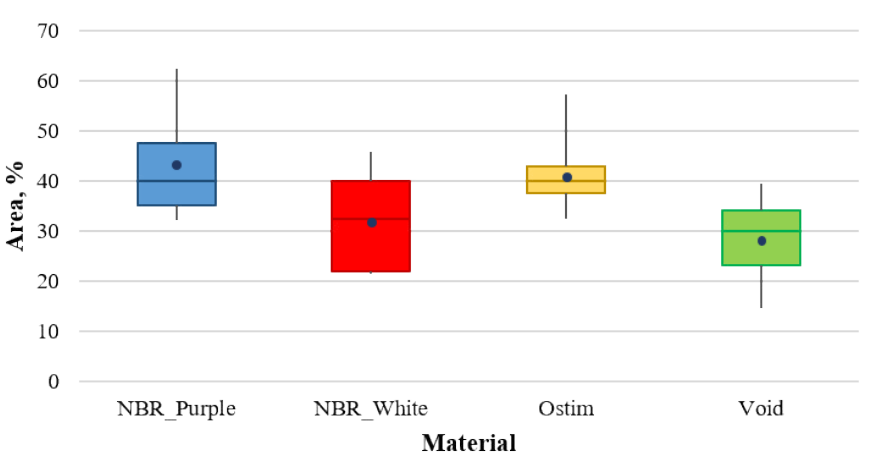

Figure 2: Box and whiskers plot of the four articles analysed at the distal site.

\section{Performance Study}

Digital pictures were obtained with a video camera (Sony, Exwave HAD) attached to a macroscope (Wild, M420) with a resolution of $97.5 \mathrm{pixel} / \mu \mathrm{m}$ at $7.8 \mathrm{x}$ magnification. The squared region of interest was defined as centred at the middle point of the implant and with a 4 -mm side, which it is twice the size of the bone defect diameter. Image processing techniques based on mathematical morphology was implemented in programming macros to specifically threshold the trabecular bone to calculate $\%$ area occupied by this tissue [29,30] (ImageJ, 1.49d, Rasband, W.S., U. S. National Institutes of Health, Bethesda, Maryland, USA, http://imagej.nih.gov/ij/, 1997-2014). Five slides of every condyles (left and right) including all materials (NBR_Purple, NBR_White, Ostim, void) were studied.

\section{Statistical Analysis}

Statistical analysis of the \% area occupied by trabecular bone was conducted. To perform means comparison the method employed is one-way analysis of means (not assuming equal variances) and the pairwise comparisons between materials using $t$ tests with pooled standard deviations ( $\mathrm{R}$, version 2.15.1, The R Foundation for Statistical Computing). Statistical analysis of bone regeneration within the defect is presented as box plot. The box represent the 25 and 75 percentiles and the horizontal line in the box represents median value. Lines outside the box represent minimum and maximum values [31]. Average value is represented as a blue point.

\section{Proximal}

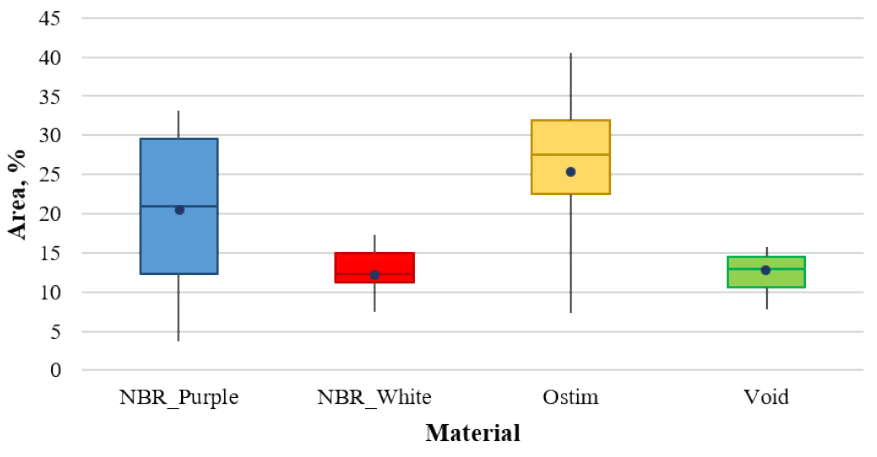

Figure 3: Box and whiskers plot of the four articles analysed at the proximal site.

Table 5: Macroscopic observation.

\begin{tabular}{|l|l|l|}
\hline Animal number & Left leg & Right leg \\
\hline 481 & Implant site and muscle were macroscopically normal & Implant site and muscle were macroscopically normal \\
\hline 482 & Implant site and muscle were macroscopically normal & Implant site and muscle were macroscopically normal \\
\hline 483 & Implant site and muscle were macroscopically normal & Implant site and muscle were macroscopically normal \\
\hline 484 & Implant site and muscle were macroscopically normal & Implant site and muscle were macroscopically normal \\
\hline 486 & Implant site and muscle were macroscopically normal & Implant site and muscle were macroscopically normal \\
\hline 487 & Implant site and muscle were macroscopically normal & Implant site and muscle were macroscopically normal \\
\hline 488 & Implant site and muscle were macroscopically normal & Implant site and muscle were macroscopically normal \\
\hline 489 & Implant site and muscle were macroscopically normal & \\
\hline
\end{tabular}




\section{Results}

\section{Macroscopic Observation}

All animals gained weight over the course of the study. Eschar and skin lesions associated with the incision lines were observed for most incisions. These skin lesions were considered a common occurrence associated with surgery at this site in rabbits and did not represent any adverse reaction to the tested biomaterials (Table 5). In the weeks following the surgery, incision sites in all animals were perfectly closed and furs cover the waxed area. Only animal 481 on day 1 showed an opened end that needed a second suture following the standard suture procedure. In this case, skin wound evolution was also good. An antiseptic was applied to the sites to prevent any possible infection and all sites healed without further complications.

\section{Microscopic Evaluation}

\section{Evaluation of Local Effects After Implantation}

Osteointegration efficacy was evaluated implanting NBR_Purple material in the medial condyle of the femur bone of rabbits for 56 days. NBR_Purple was compared with a NBR_White bone filler, without polyphenols extract, and a commercial bone filler Ostim * At 56 days of implantation, a non-irritant response (index=0.0) was seen with the test (NBR_Purple) as compared to the control bone filler (NBR_White) following the comparison procedure proposed by Annex E, ISO 10993-6.

In Figure 2 are reported the percentage of area occupied by trabecular bone after 56 days of implantation, for NBR_Purple, NBR_White, Void and Ostim material, at distal site. NBR_Purple and Ostim showed the best results ( $42.9 \pm 10.6$ and $40.7 \pm 5.9$, respectively) followed by NBR_White $(32.0 \pm 9.2)$ and Void $(28.3 \pm 8.1)$. For NBR_ Purple, there were significant differences with NBR_White and Void and there were no significant differences between NBR_Purple and Ostim (Tables 6 and 7).

Figure 3 shows the percentage of area occupied by trabecular bone at proximal site, Ostim showed the best results $(25.7 \pm 10.6)$ followed by NBR_Purple $(20.3 \pm 10.1)$ and NBR_White $(12.9 \pm 2.2)$. Tables 8 and 9 report the statistical analysis among the bone filler.

In all cases, higher value of area occupied by trabecular bone are observed at distal site by comparison with proximal site. This observation could be due as it is an area with more density of trabecular bone. Besides, proximal zone is very close to the beginning of the medullary canal and the dispersion of the material in this canal could be more frequent than expected.

Figure 4 reported the histological images for the specimens' number 487I, NBR_Purple bone filler. An area of $3.20 \mathrm{~mm}$ of diameter with several new-formed spongy bone tissue could be observed. This tissue contained small and isolates biomaterial deposits. In some locations, fatty tissue and macrophages could be observed. Several bone-forming and bone-resorption cells could be observed (Figure $4 \mathrm{~A}-4 \mathrm{C})$.
The same sample, 487I, is represented in Figure 5 for NBR_White. Histological images of this sample presented a $3.40 \mathrm{~mm}$ diameter spheroid area with small biomaterial deposit surrounded by fatty tissue, which presented in some locations a moderate inflammatory infiltrate along with venous sinuses.

\section{Discussion}

Polyphenols are attracting more and more attention in the field of bone regeneration thanks to their anti-oxidant and antiinflammatory properties $[15,32,33]$. In particular, in the field of oral health, clinical evidence has shown that flavanoids have beneficial effect on periodontitis [17-19,34], an oral inflammatory disease of polymicrobial origin that causes the disruption of gingival connective tissue and the alveolar bone supporting the teeth. Commercially available bone filler materials work through a simple scaffolding effect, providing osteoconduction. The new approach involving the biomolecular modification of biomaterials aims at enhancing the host tissue response through biologically active molecules delivered from the device or linked to the device surface [35-38]. In this broad scenario, the use of polyphenols from different source is widely investigated [32,39-45]. Grape pomace is an interesting source of polyphenols, and polyphenols-rich pomace extract are of particular interest due to the heterogeneity of the mixture, which makes these extract extremely interesting, since it contains a large number of polyphenols classes. Potentially beneficial effects of polyphenols have been reported in various study. For example, cell biology and in vivo

Table 6: Statistics descriptive at distal site.

\begin{tabular}{|l|c|c|c|c|c|}
\hline \multicolumn{7}{|c|}{ Distal } \\
\hline Material & Valid N & Minimum & Maximum & Mean & St. Dev. \\
\hline NBR_Purple & 22 & 32.11 & 62.48 & 42.92 & 10.65 \\
\hline Ostim & 21 & 32.3 & 57.22 & 40.67 & 5.95 \\
\hline NBR_White & 21 & 21.41 & 45.91 & 32.04 & 9.19 \\
\hline Void & 20 & 14.47 & 39.51 & 28.28 & 8.15 \\
\hline
\end{tabular}

Table 7: Pairwise comparison at distal site using t test with pooled standard deviation.

\begin{tabular}{|l|c|c|c|}
\hline & NBR_Purple & NBR_White & Ostim \\
\hline NBR_White & $<0.001$ & - & - \\
\hline Ostim & 0.39773 & 0.00187 & - \\
\hline Void & $<0.001$ & 0.16914 & $<0.001$ \\
\hline
\end{tabular}

Table 8: Statistics descriptive at proximal site.

\begin{tabular}{|l|c|c|c|c|c|}
\hline \multicolumn{7}{|c|}{ Statistic Description } \\
\hline Material & Valid N & Minimum & Maximum & Mean & St. Dev. \\
\hline NBR_Purple & 20 & 3.63 & 33.13 & 20.26 & 10.11 \\
\hline Ostim & 21 & 7.35 & 40.52 & 25.73 & 10.62 \\
\hline NBR_White & 20 & 7.43 & 17.40 & 12.92 & 2.88 \\
\hline Void & 21 & 7.75 & 15.71 & 11.96 & 2.16 \\
\hline
\end{tabular}

Table 9: Pairwise comparison at proximal site using t test with pooled standard deviation.

\begin{tabular}{|l|c|c|c|}
\hline & NBR_Purple & NBR_White & Ostim \\
\hline NBR_White & 0.00294 & - & - \\
\hline Ostim & 0.02309 & $<0.001$ & - \\
\hline Void & $<0.001$ & 0.68414 & $<0.001$ \\
\hline
\end{tabular}


A

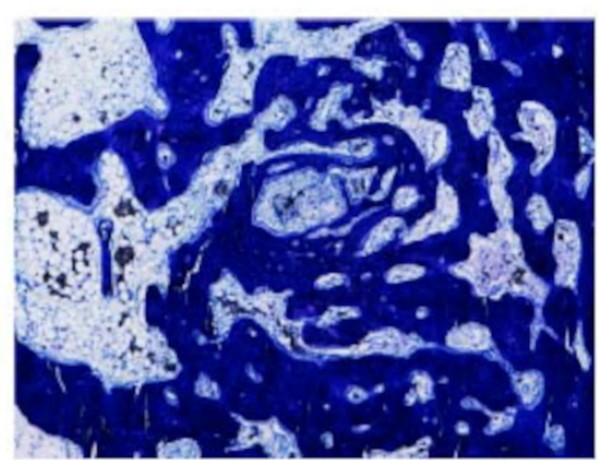

[

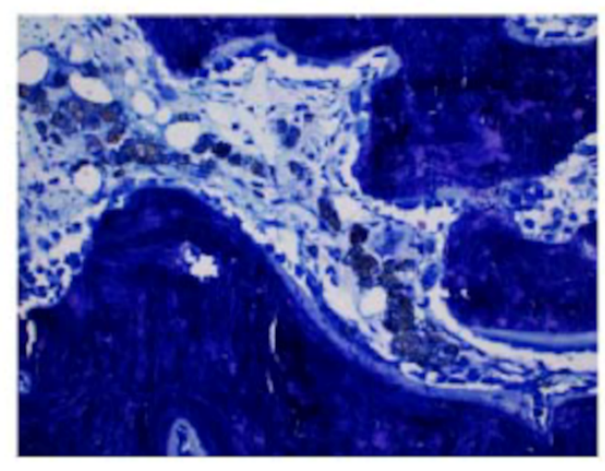

B

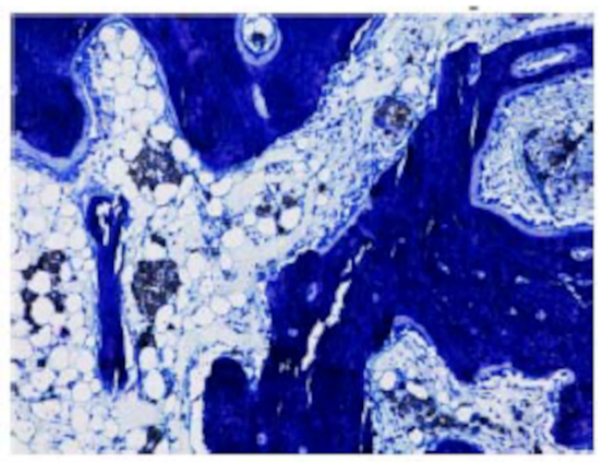

Figure 4: Histological section of NBR_Purple implanted in sample 487I.

A

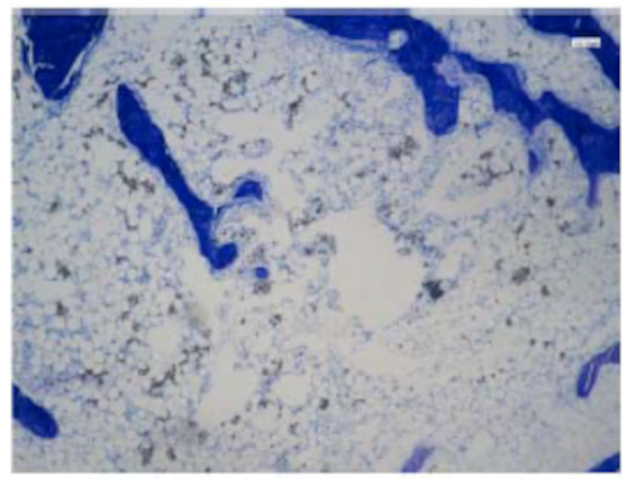

B

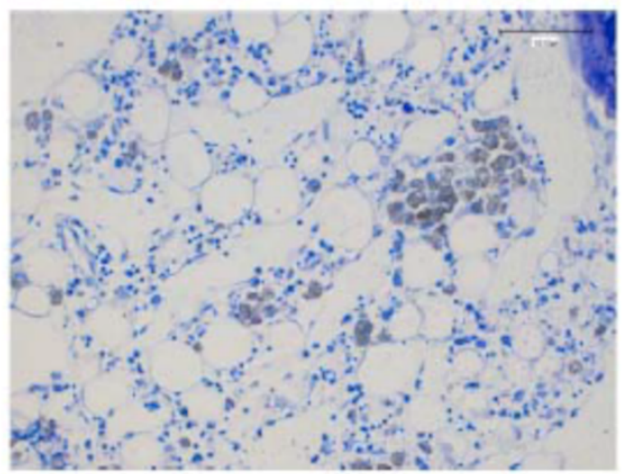

Figure 5: Histological section of NBR_White implantend in sample 487I.

rodent model studies $[34,46,47]$ have demonstrated that flavanoids regulated the inflammatory response in periodontal components, and preserve effects on periodontal ligaments and alveolar bone tissues [48]. Another class of polyphenols, proanthocyanidins, has been shown both in vitro and in vivo to have a protective effect against oxidative stress and periodontitis $[15,49]$. The role of polyphenols in molecular signalling mechanisms behind bone anabolism has been recently reviewed [50] and potentials of polyphenols in bone-implant devices have been described [51].

Based on existing literature evidences, in the present work, a polyphenols-rich pomace extract combined to a biphasic phosphate ceramic bone filler was tested in vivo and compared to the same material without polyphenols and a couple of other controls. The study demonstrates in vivo that the presence of polyphenols enhances the osteointegration of the calcium phosphate bone filler. The results show that there is an higher value of the area occupied by trabecular bone after 56 days by the bone filler with polyphenols (NBR_Purple) and the bone filler without polyphenols (NBR_White). These results, support the several studies that have investigated the ability of polyphenols to improve and maintain bone health, showing clear positive effects on bone regeneration.

\section{Conclusion}

The study here reported demonstrates that at 56 days after implantation at distal and proximal sites in rabbit femoral condyles, the polyphenols-enriched bone filler NBR_Purple shows higher value of trabecular bone regeneration than those of the same material without polyphenols NBR_White. Assuming that the trabecular bone regeneration in an empty defect (Void condition) could be considered as physiological trabecular bone regeneration after a bone defect creation, NBR_Purple showed a 1.5 times regeneration enhancement at distal site and 2.1 times regeneration enhancement at proximal site. Present in vivo data support the role of polyphenols molecules in the stimulation of bone regeneration mechanisms. 


\section{Reference}

1. Figueiredo M, Henriques J, Martins G, Guerra F, Judas F, et al. (2010) Physicochemical characterization of biomaterials commonly used in dentistry as bone substitutes Comparison with human bone. J Biomed Mater Res - Part B Appl Biomater 2: 409419. [crossref]

2. Iviglia G, Kargozar S, Baino F (2019) Biomaterials, current strategies, and novel nano-technological approaches for periodontal regeneration. J Funct Biomater 1: 3. [crossref]

3. Tadic D (2004) A thorough physicochemical characterisation of 14 calcium phosphate-based bone substitution materials in comparison to natural bone. Biomaterials 6: 987-994. [crossref]s

4. Samavedi S, Whittington AR, Goldstein AS (2013) Calcium phosphate ceramics in bone tissue engineering: A review of properties and their influence on cell behavior. Acta Biomater 9: 8037-8045. [crossref]

5. Iviglia G, Morra M, Cassinelli C, Torre E, Rodriguez Y, et al. (2018) New collagencoated calcium phosphate synthetic bone filler $\left(\right.$ Synergoss $\left.^{\circledR}\right)$ : A comparative surface analysis. Int J Appl Ceram Technol 4: 910-920.

6. Zhang L, Hanagata N, Maeda M, Minowa T, Ikoma T, et al. (2009) Porous hydroxyapatite and biphasic calcium phosphate ceramics promote ectopic osteoblast differentiation from mesenchymal stem cells. Sci Technol Adv Mater 2: 025003.

7. Cantos E, Espín JC, Tomás-Barberán FA (2002) Varietal differences among the polyphenol profiles of seven table grape cultivars studied by LC-DAD-MS-MS. J Agric Food Chem 20: 5691-5696. [crossref]

8. Rothwell J, Pérez-Jiménez J, Neveu V, A M-R, N M, et al. (2013) Phenol-Explorer 3.0: a major update of the Phenol-Explorer database to incorporate data on the effects of food processing on polyphenol content. Database 2013: 070. [crossref]

9. Yamaguchi M, Ma ZJ (2001) Effect of Polyphenols on Calcium Content and Alkaline Phosphatase Activity in Rat Femoral Tissues in Vitro. Biol Pharm Bull 12: 1437-1439. [crossref]

10. Hämäläinen $M$, Nieminen R, Vuorela P, Heinonen M, Moilanen E (2007) Antiinflammatory effects of flavonoids: Genistein, kaempferol, quercetin, and daidzein inhibit STAT-1 and NF- $\mathrm{kB}$ activations, whereas flavone, isorhamnetin, naringenin, and pelargonidin inhibit only NF- $\mathrm{kB}$ activation along with their inhibitory effect on iNOS expression and NO production in activated macrophages. Mediators Inflamm 2007: 45673. [crossref]

11. Yamaguchi M, Arbiser JL, Weitzmann MN (2011) Honokiol stimulates osteoblastogenesis by suppressing NF- $\mathrm{KB}$ activation. Int J Mol Med 6: 1049-1053. [crossref]

12. Prouillet C, Mazière JC, Mazière C, Wattel A, Brazier M, et al. (2004) Stimulatory effect of naturally occurring flavonols quercetin and kaempferol on alkaline phosphatase activity in MG-63 human osteoblasts through ERK and estrogen receptor pathway. Biochem Pharmacol 7: 1307-1313. [crossref]

13. Miyake M, Arai N, Ushio S, Iwaki K, Ikeda M, et al. (2003) Promoting Effect of Kaempferol on the Differentiation and Mineralization of Murine Pre-osteoblastic Cell Line MC3T3-E1. Biosci Biotechnol Biochem 6: 1199-1205. [crossref]

14. Govindaraj J, Emmadi P, Puvanakrishnan R (2010) In vitro studies on inhibitory effect of proanthocyanidins in modulation of neutrophils and macrophages. Indian J Biochem Biophys 3: 141-147.

15. Govindaraj J, Emmadi P, Deepalakshmi, Rajaram V, Prakash G, et al. (2010) Protective effect of proanthocyanidins on endotoxin induced experimental periodontitis in rats. Indian J Exp Biol 2: 133-142. [crossref]

16. Govindaraj J, Emmadi P, Puvanakrishnan R (2011) Therapeutic effects of proanthocyanidins on the pathogenesis of periodontitis--an overview. Indian J Exp Biol 2: 83-93. [crossref]

17. Palaska I, Papathanasiou E, Theoharides TC (2013) Use of polyphenols in periodontal inflammation. Eur J Pharmacol 720: 77-83. [crossref]

18. Leena Sankari S, Aravindha Babu N, Rani V, Priyadharsini C, Masthan KMK (2014) Flavonoids-Clinical effects and applications in dentistry: A review. J Pharm Bioallied Sci 1: 26-29.

19. Bunte K, Hensel A, Beikler T (2019) Polyphenols in the prevention and treatment of periodontal disease: A systematic review of in vivo, ex vivo and in vitro studies. Fitoterapia: 30-39. [crossref]
20. Shen C-L, Wang P, Guerrieri J, Yeh JK, Wang J-S (2008) Protective effect of green tea polyphenols on bone loss in middle-aged female rats. Osteoporos Int 7: 979-990. [crossref]

21. Lee JH, Jin H, Shim HE, Kim HN, Ha H, et al. (2010) Epigallocatechin-3-gallate inhibits osteoclastogenesis by down-regulating c-Fos expression and suppressing the nuclear factor-kappaB signal. Mol Pharmacol 1: 17-25. [crossref]

22. Nakamura H, Ukai T, Yoshimura A, Kozuka Y, Yoshioka H, et al. (2010) Green tea catechin inhibits lipopolysaccharide-induced bone resorption in vivo. J Periodontal Res 1: 23-30. [crossref]

23. Gómez-Florit M, Monjo M, Ramis JM (2014) Identification of quercitrin as potential therapeutic agent for periodontal applications. J Periodontol 7: 966-974. [crossref]

24. Vitale-Brovarone C, Baino F, Verné E (2009) High strength bioactive glass-ceramic scaffolds for bone regeneration. J Mater Sci Mater Med 2: 643-653. [crossref]

25. Vitale-Brovarone C, Verné E, Robiglio L, Appendino P, Bassi F, et al. (2007) Development of glass-ceramic scaffolds for bone tissue engineering: characterisation, proliferation of human osteoblasts and nodule formation. Acta Biomater 2: 199-208. [crossref]

26. Torre E, Iviglia G, Cassinelli C, Morra M, Russo N (2020) Polyphenols from grape pomace induce osteogenic differentiation in mesenchymal stem cells. Int J Mol Med 6: 1721-1734. [crossref]

27. ISO/EN10993-6 (2007) Biological evaluation of medical devices - Part 6: Tests for local effects after implantation. Int Organ Stand.

28. Peris Serra J, Prat Pastor J, Comín Clavijo M, Dejoz R, Roger I, et al. (1993) Técnica histológica para la inclusión en metilmetacrilato de muestras óseas no descalcificadas. Rev española cirugía Osteoartic 166: 231-238.

29. Huber FX, Berger I, McArthur N, Huber C, Kock HP, et al. (2008) Evaluation of a novel nanocrystalline hydroxyapatite paste and a solid hydroxyapatite ceramic for the treatment of critical size bone defects (CSD) in rabbits. J Mater Sci Mater Med 1: 33-38. [crossref]

30. Huber FX, McArthur N, Heimann L, Dingeldein E, Cavey H, et al. (2009) Evaluation of a novel nanocrystalline hydroxyapatite paste Ostim in comparison to Alpha-BSM - more bone ingrowth inside the implanted material with Ostim compared to Alpha BSM. BMC Musculoskelet Disord 10: 164. [crossref]

31. Luo T, Wu C, Zhang Y (2012) The in vivo osteogenesis of Mg or Zr-modified silicatebased bioceramic spheres. J Biomed Mater Res - Part A 9: 2269-2277. [crossref]

32. Córdoba A, Satué M, Gómez-Florit M, Hierro-Oliva M, Petzold C, et al. (2015) Flavonoid-modified surfaces: Multifunctional bioactive biomaterials with osteopromotive, anti-inflammatory, and anti-fibrotic potential. Adv Healthc Mater 4: 540-549. [crossref]

33. Torre E (2017) Molecular signaling mechanisms behind polyphenol-induced bone anabolism. Phytochem Rev 6: 1183-1226. [crossref]

34. Özden FO, Sakallioğlu EE, Sakallioğlu U, Ayas B, Erişgin Z (2017) Effects of grape seed extract on periodontal disease: An experimental study in rats. J Appl Oral Sci 2: 121-129. [crossref]

35. Morra M (2007) Biomolecular modification of implant surfaces. Expert Rev Med Devices 3: 361-72. [crossref]

36. Brett E, Flacco J, Blackshear C, Longaker MT, Wan DC (2017) Biomimetics of Bone Implants: The Regenerative Road. Biores Open Access 1: 1-6.

37. Morra M, Cassinelli C, Torre E, Iviglia G (2018) Permanent wettability of a novel, nanoengineered, clinically available, hyaluronan-coated dental implant. Clin Exp Dent Res 5: 196-205.

38. Bryers JD, Giachelli CM, Ratner BD (2012) Engineering biomaterials to integrate and heal: The biocompatibility paradigm shifts. Biotechnol Bioeng 8: 1898-1911. [crossref]

39. Zhang X, Ferraris S, Prenesti E, Verné E (2013) Surface functionalization of bioactive glasses with natural molecules of biological significance, part II: Grafting of polyphenols extracted from grape skin. Appl Surf Sci : 341-348.

40. Gomez-Florit M, Pacha-Olivenza MA, Fernández-Calderón MC, Córdoba A, González-Martín ML, et al. (2016) Quercitrin-nanocoated titanium surfaces favour gingival cells against oral bacteria. Sci Rep 1: 22444.

41. Gómez-Florit M, Monjo M, Ramis JM (2015) Quercitrin for periodontal regeneration: effects on human gingival fibroblasts and mesenchymal stem cells. Sci Rep 5: 16593. [crossref] 
42. Cazzola M, Corazzari I, Prenesti E, Bertone E, Vernè E, et al. (2016) Bioactive glass coupling with natural polyphenols: Surface modification, bioactivity and antioxidant ability. Appl Surf Sci : 237-248.

43. Cazzola M, Vernè E, Cochis A, Sorrentino R, Azzimonti B, et al. (2017) Bioactive glasses functionalized with polyphenols: in vitro interactions with healthy and cancerous osteoblast cells. J Mater Sci 15: 9211-9223.

44. Cazzola M, Ferraris S, Boschetto F, Rondinella A, Marin E, et al. (2018) Green tea polyphenols coupled with a bioactive titanium alloy surface: In vitro characterization of osteoinductive behavior through a KUSA A1 cell study. Int J Mol Sci 8: 2255. [crossref]

45. Tsuchiya S, Sugimoto K, Kamio H, Okabe K, Kuroda K, et al. (2018) Kaempferolimmobilized titanium dioxide promotes formation of new bone: Effects of loading methods on bone marrow stromal cell differentiation in vivo and in vitro. Int $J$ Nanomedicine 13: 1665-1676. [crossref]

46. Gennaro G, Claudino M, Cestari TM, Ceolin D, Germino P, et al. (2015) Green tea modulates cytokine expression in the periodontium and attenuates alveolar bone resorption in type 1 diabetic rats. PLoS One 8: 0134784. [crossref]
47. Tominari T, Matsumoto C, Watanabe K, Hirata M, Grundler FMW, et al (2015) Epigallocatechin gallate (EGCG) suppresses lipopolysaccharide-induced inflammatory bone resorption, and protects against alveolar bone loss in mice. FEBS Open Bio 5: 522-527. [crossref]

48. Fernández-Rojas B, Gutiérrez-Venegas G (2018) Flavonoids exert multiple periodontic benefits including anti-inflammatory, periodontal ligament-supporting, and alveolar bone-preserving effects. Life Sci 209: 435-454. [crossref]

49. Houde V, Grenier D, Chandad F (2006) Protective effects of grape seed proanthocyanidins against oxidative stress induced by lipopolysaccharides of periodontopathogens. J Periodontol 8: 1371-1379. [crossref]

50. Torre E (2017) Molecular signaling mechanisms behind polyphenol-induced bone anabolism. Phytochem Rev 6: 1183-1226. [crossref]

51. Torre E, Iviglia G, Cassinelli C, Morra M (2018) Potentials of polyphenols in boneimplant devices. In: Janica Wong, ed. Polyphenols. IntechOpen 2018. 